Research Article

\title{
Study on Pressure Relief Effect of Rock Mass with Different Borehole Parameters
}

\author{
Chao Peng $\mathbb{i D}^{1,2}$ and Wanrong Liu $\mathbb{D}^{1}$ \\ ${ }^{1}$ School of Architecture \& Civil Engineering, Liaocheng University, Liaocheng, Shandong 252059, China \\ ${ }^{2}$ School of Emergency Management and Safety Engineering, China University of Mining \& Technology (Beijing), Haidian, \\ Beijing 100083, China \\ Correspondence should be addressed to Wanrong Liu; wanrongliu1989@163.com
}

Received 1 February 2021; Revised 15 February 2021; Accepted 22 February 2021; Published 8 March 2021

Academic Editor: Zizheng Zhang

Copyright (c) 2021 Chao Peng and Wanrong Liu. This is an open access article distributed under the Creative Commons Attribution License, which permits unrestricted use, distribution, and reproduction in any medium, provided the original work is properly cited.

\begin{abstract}
Rock burst is one of the disaster accidents that can easily happen in rock cavern engineering. At present, one of the most commonly used methods to control rock burst is borehole pressure relief technology. In this paper, the influence of drilling layout schemes on the pressure relief effect of surrounding rock mass is systematically studied. The research results show that the strength reduction degree, $\mathrm{AE}$ evolution characteristics, failure modes of rock samples with different borehole positions, boreholes spacing, boreholes dip angles, and boreholes layout forms are different. The strength reduction degree of rock sample with an inclined arrangement form is the largest, followed by the arrangement form being up three-flower layout or down three-flower layout. Using the inclined layout and three-flower layout can achieve better pressure relief effect of the surrounding rock mass. The research results are beneficial to the rock burst of surrounding rock of the cavern. The acoustic emission can effectively monitor the stability of the surrounding rock of the cavern. However, the threshold value and the occurrence time of the acoustic emission of the cavern instability changed after the cavern surrounding rock is drilled holes. If the borehole is arranged at the surrounding rock mass, the occurrence time of the cavern instability may be advanced.
\end{abstract}

\section{Introduction}

With the rapid development of economy and technology as well as the increase of population, the underground rock cavern engineering has made great progress. However, as the development scale and depth increase, the frequency and intensity of rock burst and other surrounding rock dynamic disasters are also increasing, which seriously affects the safety construction and operation of cavern engineering. For the deep surrounding rock with rockburst tendency, one of the most commonly used methods to control rockburst risk is borehole pressure relief technology [1-5]. The borehole pressure relief technology is to form a weakening area in the deep part of the rock mass by means of the boreholes, to provide a release space for the accumulated energy in the rock mass, and to promote the peak value of stress concentration to transfer to the deep part of the rock mass, so as to reduce the risk of rock burst.
In the aspect of drilling pressure relief technology research, Liu et al. [3] used laboratory test, numerical simulation, and theoretical method and analyzed the mechanism of boreholes to prevent rockburst, and the research results show that the borehole spacing is a function of borehole diameter, thickness of coal seam, increasing overflow coefficient, and safety increasing variables and is also related to increasing overflow coefficient and borehole diameter. Yi et al. [6] used FLAC numerical simulation to analyze the pressure relief effect of large-diameter drilling in soft and hard coal seam; the research results show that the pressure relief effect of drilling in soft rock is better than that in hard rock. Li et al. [7] analyzed the safety parameters of the pressure relief drilling in the dangerous coal seam and found that the larger the hole diameter of the pressure relief drilling, the better the pressure relief effect. There is a critical value for the spacing of the pressure relief drilling; when the holes spacing is less than the critical value, the coal body between the two holes will be 
damaged and deformed to a greater extent, and the pressure relief effect will be good. Zhang et al. [8], based on actual geologic conditions in the area of a rock burst that occurred in the Yangcheng Mine, conducted a series of experimental studies on mechanical properties using gypsum-type coal-like materials with different numbers and configurations of pressure relief boreholes. Other scholars also conducted drilling holes to relieve pressure on coal and rock and guided certain engineering practices [9-11]. The results show that the larger the drilling density, the more the rock fracture development around the boreholes, and the greater the energy release and, hence, the more effective the relief effect. These researches are of great significance to alleviate the rock burst risk of surrounding rock of cavern; however, there are few systematic researches on the influence of drilling layout schemes on the pressure relief effect.

Based on the above research, this paper studies the influence of drilling layout schemes on the pressure relief effect of surrounding rock mass. Firstly, the rock models of different drilling layout schemes are established by means of particle flow code (PFC); secondly, the influences of different borehole positions, boreholes spacing, boreholes dip angles, and boreholes layout forms on the strength reduction characteristics, acoustic emission evolution characteristics, and failure modes of rock samples are analyzed. The research results are beneficial to the rock burst of surrounding rock of the cavern.

\section{Numerical Test Scheme}

2.1. Particle Flow Code (PFC) Theory. The particle flow code theory was firstly introduced by Cundall and Strack [12] based on discrete element method. The basic compositions of the PFC model are particles and bonds, and the geometrical and mechanical properties of the particles and bonds determined the macroscopic mechanical properties of the models [13]. The bonded contact constitutive model was widely used in numerical simulation of rock and soil materials [14-17]. There are two kinds of modes of the bonds, named contact bond and parallel bond. The contact bonding is point contact; it can only transfer force, but not force moment. The contact position of the parallel bond model is a rectangular section, as shown in Figure 1, which can transfer both force and moment. Therefore, the parallel bond model is more suitable for the simulation of rock materials.

The contact force of parallel bond particles can be expressed by the following formula:

$$
\overline{F_{i}}=\bar{F}_{i}^{n}+\bar{F}_{i}^{s},
$$

where $\bar{F}_{i}^{s}$ is the shear contact force and $\bar{F}_{i}^{n}$ is the normal contact force.

In the process of calculation, no matter it is normal force, shear force, or moment, the increment will be generated. The increment in each time step is expressed as [13]

$$
\left\{\begin{array}{l}
\Delta \bar{F}_{i}^{n}=\left(-\bar{k}^{n} A \Delta U^{n}\right) n_{i}, \\
\Delta \bar{F}_{i}^{s}=-\bar{k}^{s} A \Delta U_{i}^{s}, \\
\Delta \bar{M}_{3}=-\bar{k}^{n} I \Delta \theta_{3},
\end{array}\right.
$$

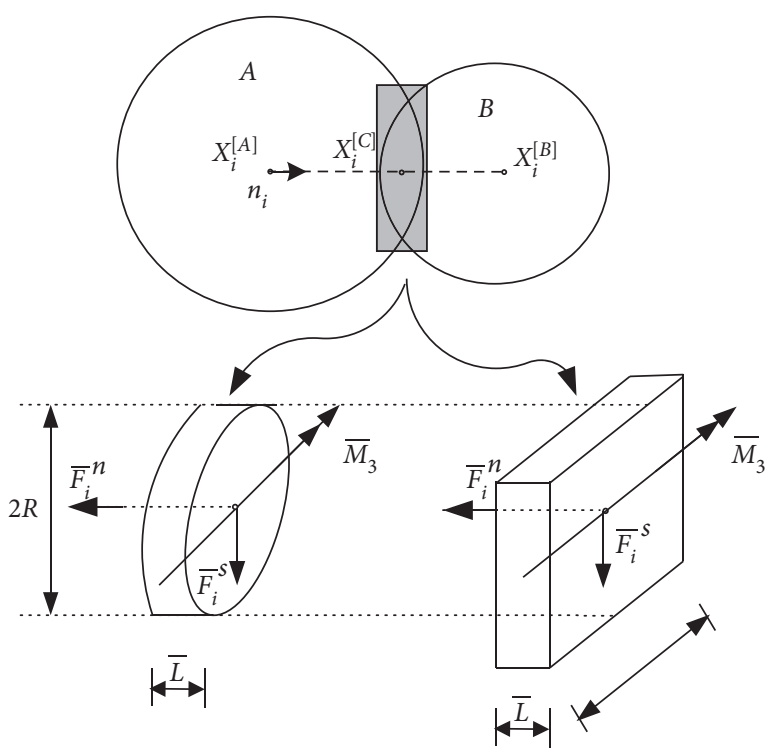

Figure 1: Parallel bond models [13].

where $\bar{k}^{n}$ is the normal stiffness and $\bar{k}^{s}$ is the shear stiffness. $n_{i}$ is the normal vector of the contact point. $A$ is the area of the parallel bond surface. $\bar{M}$ is the moment. During the calculation, the force and moment are continuously updated for each iteration, until the specified balance condition is reached, the calculation stopped, and the new force and moment expressions are as follows:

$$
\left\{\begin{array}{l}
\bar{F}_{i}^{n} \leftarrow \bar{F}^{n} n_{i}+\Delta \bar{F}_{i}^{n}, \\
\bar{F}_{i}^{s} \leftarrow \bar{F}^{s}+\Delta \bar{F}_{i}^{s}, \\
\bar{M}_{3} \leftarrow \bar{M}_{3}+\Delta \bar{M}_{3} .
\end{array}\right.
$$

During the calculation process, when the external force exceeds the normal bond strength or the shear bond strength of the parallel bond, the parallel bond will break, and then tension or shear crack will occur.

2.2. Model Parameter Checking. Usually, the microparameters of PFC rock models are calibrated by simulating the uniaxial compression experiments [14]. During the process of calibration, the microparameters of the particles and bonds are adjusted many times through "trial-and-error" method [13] until these parameters can better reflect the mechanical properties of the real rocks. In this manuscript, the model parameters were checked with a sandstone based on "trial-and-error" method. Through repeated trial and error, the parameters in Table 1 can simulate the sandstone well, as shown in Figures 2 and 3. It can be seen that the elastic modulus (E) and uniaxial compressive strength (UCS) of the numerical simulation are basically consistent with the experimental test of the sandstone. However, the stress-strain curves of laboratory tests and numerical simulations showed a certain deviation at the beginning. The main reason is that the indoor samples contain original cracks. 
TABle 1: Physicomechanical parameters of numerical test model.

\begin{tabular}{lc}
\hline Parameter & Value \\
\hline Minimum particle diameter $(\mathrm{mm})$ & 0.3 \\
Maximum particle diameter $(\mathrm{mm})$ & 0.5 \\
Parallel bond tensile strength $(\mathrm{MPa})$ & 22 \\
Parallel bond cohesive force $(\mathrm{MPa})$ & 56.5 \\
Stiffness ratio & 1.51 \\
Contact bond gap $(\mathrm{mm})$ & 0.05 \\
Density $\left(\mathrm{kg} / \mathrm{m}^{3}\right)$ & 2500 \\
Contact modulus of the particle $(\mathrm{GPa})$ & 10.2 \\
Parallel bond deformation modulus $(\mathrm{GPa})$ & 16.2 \\
Porosity & 0.1 \\
\hline
\end{tabular}

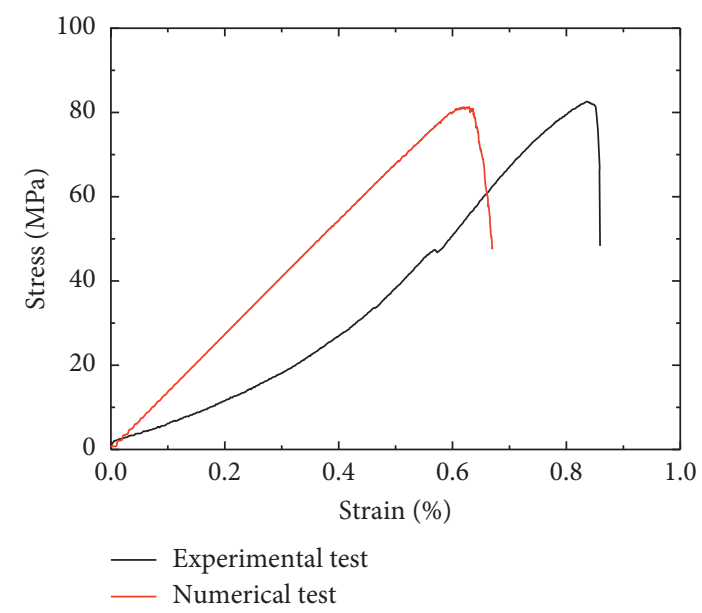

FIGURE 2: Stress-strain curves of sandstone based on experimental and numerical tests.

2.3. Test Schemes. In order to systematically explore the influence of drilling layout schemes on the pressure relief effect of rock burst prone surrounding rock mass, this paper considered the following four simulation schemes according to the actual drilling characteristics. The size of these models is $50 \mathrm{~mm}$ (width) $\times 100 \mathrm{~mm}$ (height) and the parameters of them is the same as in Table 1 . The process of establish the models is as follows: (1) establish complete rock models, which have the same particle distribution form and the same mechanical properties; (2) according to the test schemes, delete some particles to simulation drilling holes, and all the drilling holes have the same diameter of $6 \mathrm{~mm}$.

2.3.1. Models of Different Borehole Locations. Because the height of the cavern is known in the actual engineering, the ratio $(R)$ of the borehole height $(h)$ to the tunnel height $(H)$ is used to determine the location of the borehole quantitatively, and it is defined as borehole height ratio. In order to study the influence of borehole location on the pressure relief effect of cavern surrounding rock mass, numerical models of different borehole location are established, as shown in Figure 4. The borehole height ratio $R(=h / H)$ are considered as $0.1,0.3,0.5,0.7$, and 0.9, respectively.
2.3.2. Models of Different Boreholes Spacing. In order to study the influence of boreholes spacing $S$ on the pressure relief effect of cavern surrounding rock mass, rock models with double boreholes were established (as shown in Figure 5) and the $S$ are considered as $1 D, 2 D, 4 D, 6 D$, and $8 D$, respectively. $D$ is the diameter of boreholes.

2.3.3. Models of Different Boreholes Dip Angles. In order to study the influence of boreholes dip angle $\alpha$ on the pressure relief effect of cavern surrounding rock mass, rock models with double boreholes were established (as shown in Figure 6) and $\alpha$ are considered as $0^{\circ}, 20^{\circ}, 40^{\circ}, 60^{\circ}$, and $80^{\circ}$, respectively.

\subsubsection{Models of Different Boreholes Arrangement Forms.} In order to study the influence of boreholes arrangement form on the pressure relief effect of cavern surrounding rock mass, rock models with three boreholes were established (as shown in Figure 7) and the arrangement form are considered as vertical layout $(V)$, horizontal layout $(H)$, inclined layout $(I)$, up three-flower layout $(U)$, and down three-flower layout (D), respectively.

After the models are built, the uniaxial compression tests are carried out through the wall set at the top of the models. The displacement control model is used for loading. During the loading process, the stress, strain, and crack growth characteristics of the models are monitored by fish language.

\section{Analysis of Test Results}

3.1. Strength Reduction Characteristics. The peak stress intensity can well reflect the pressure relief effect of the rock mass. Therefore, the peak stress is used to analyze the pressure relief effect.

3.1.1. Influence of Borehole Locations. Figures 8 and 9 are stress-strain curves and strength reduction curves of rock samples with different drilling positions. From the figures it can be seen that, in addition to the sample that the drill hole is at the end face of the rock bottom $(R=0.1)$, the closer the drilling hole is to the top of the rock sample, that is, the larger $R$ value is, the lower the strength of the rock is, and the higher the strength reduction degree of the rock sample is. When $R$ increase from 0.3 to 0.9 , the strengths of rock samples are 77.07 $\mathrm{MPa}, 74.24 \mathrm{MPa}, 70.49 \mathrm{MPa}$, and $57.87 \mathrm{MPa}$ and the corresponding strength reduction degrees are $4.9 \%, 8.4 \%$, $13 \%$, and $28.6 \%$. The reason is that the upper and lower end faces of rock sample are prone to producing stress concentration in the process of loading, which makes drilling at the end easy to damage the rock sample. Therefore, it is easy to reduce the stress concentration of surrounding rock mass by drilling at the top and bottom of the cavern, which can effectively prevent rock burst.

3.1.2. Influence of Boreholes Spacing. Figures 10 and 11 are stress-strain curves and strength reduction curves of rock samples with different boreholes spacing. From the figures it 


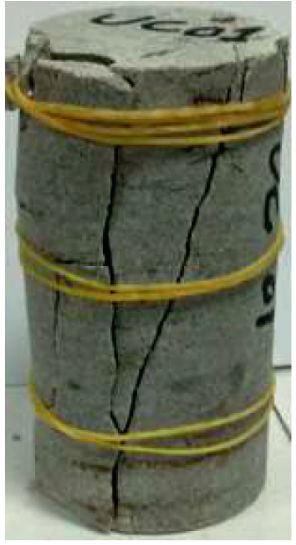

(a)

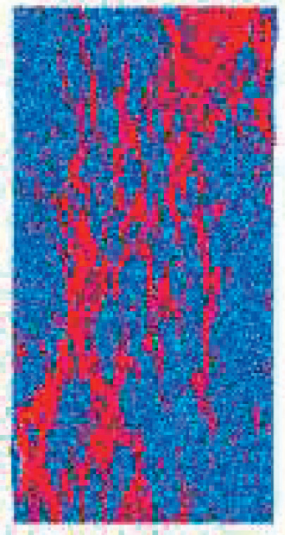

(b)

FIGURE 3: Failure modes of sandstone based on experimental and numerical tests: (a) experimental test; (b) numerical test.

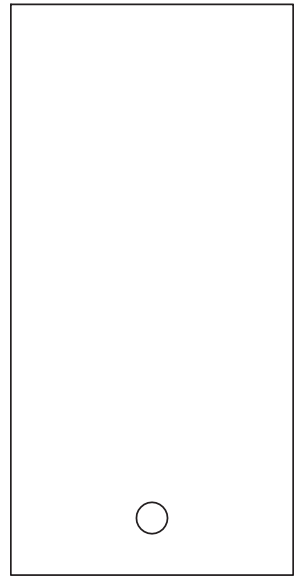

(a)

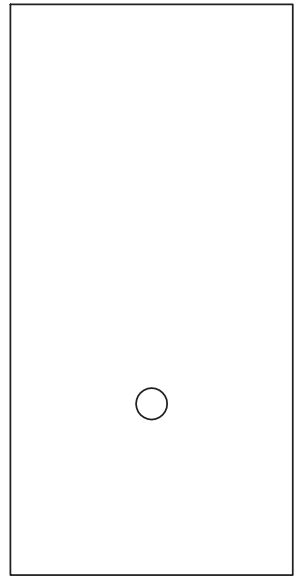

(b)

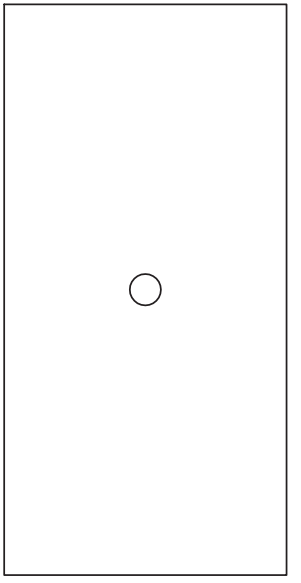

(c)

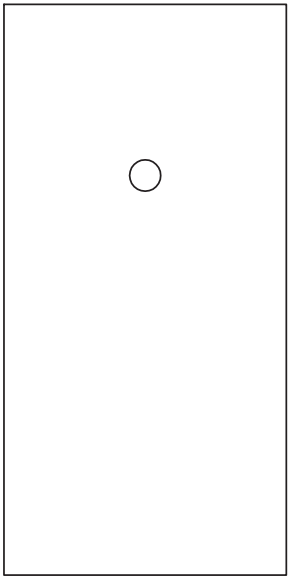

(d)

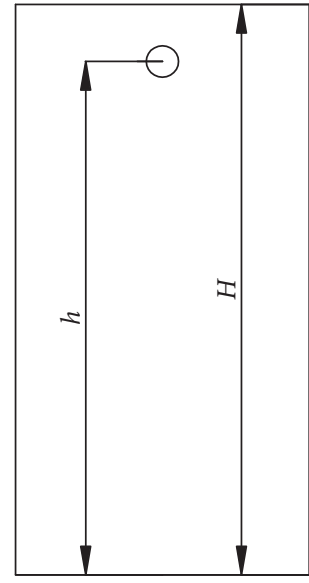

(e)

Figure 4: Numerical test samples with different borehole height ratio. The $R$ of (a), (b), (c), (d), and (e) are 0.1, 0.3, 0.5, 0.7, and 0.9, respectively.

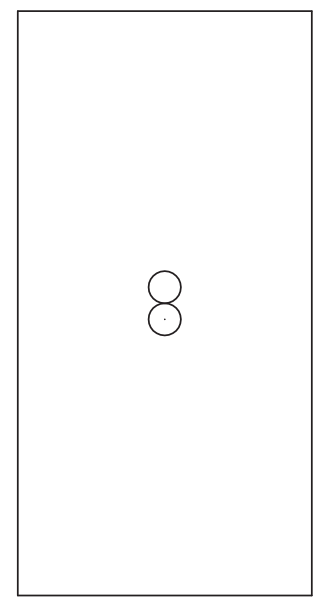

(a)

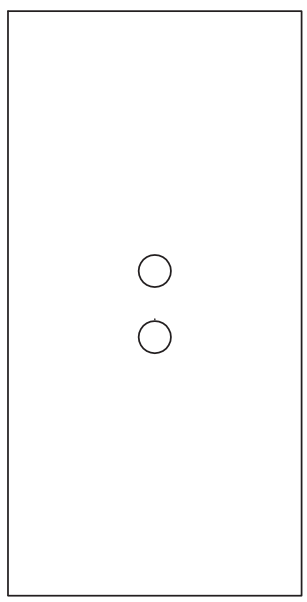

(b)

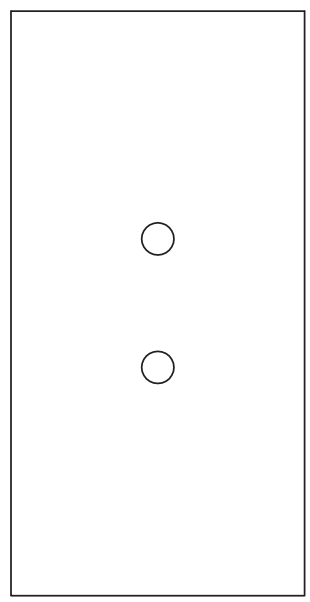

(c)

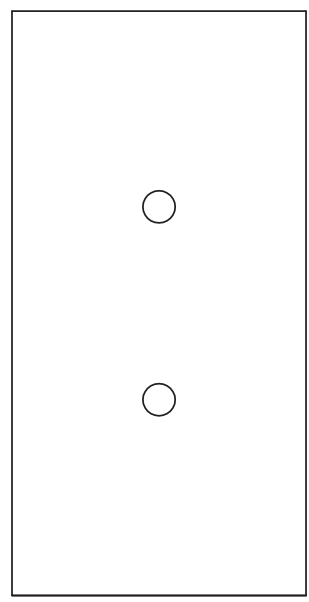

(d)

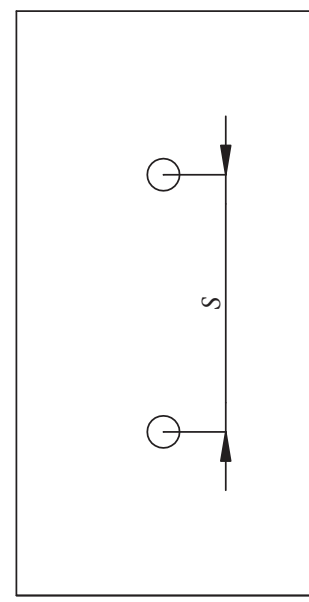

(e)

Figure 5: Numerical test samples with different boreholes spacing. The $S$ of (a), (b), (c), (d), and (e) are $1 D, 2 D, 4 D, 6 D$, and $8 D$, respectively. 


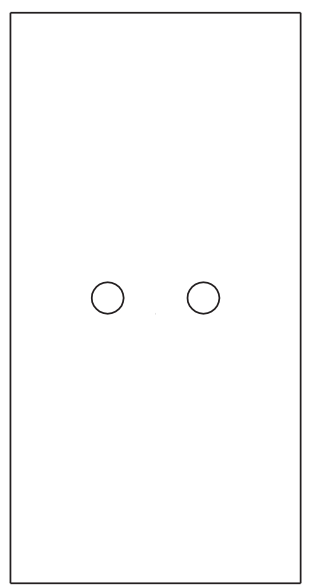

(a)

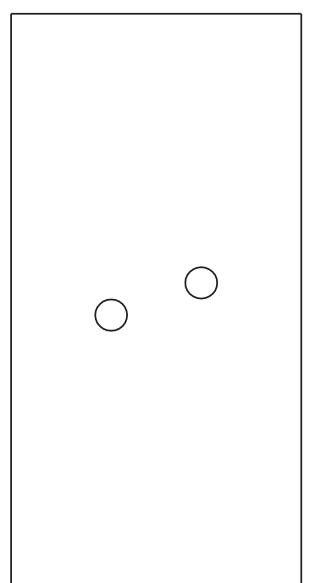

(b)

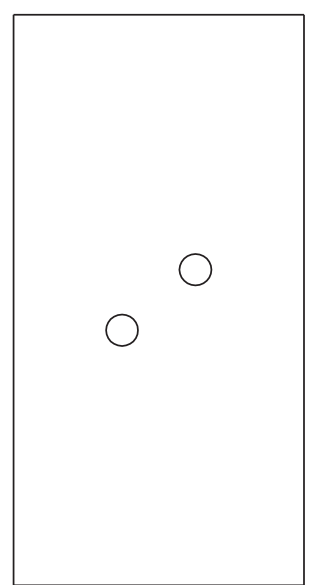

(c)

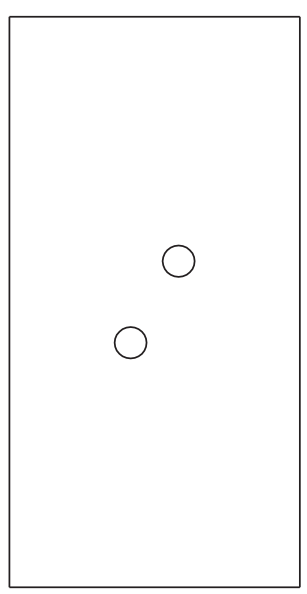

(d)

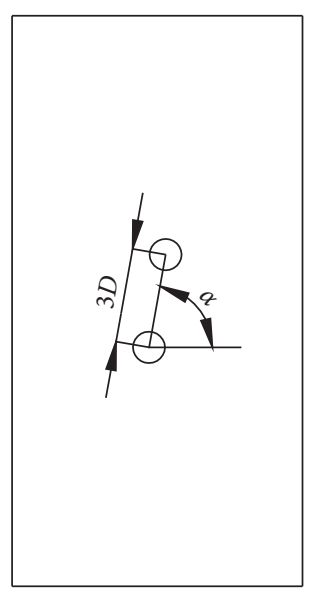

(e)

Figure 6: Numerical test samples with different boreholes dip angle. $\alpha$ of (a), (b), (c), (d), and (e) are $0^{\circ}, 20^{\circ}, 40^{\circ}, 60^{\circ}$, and $80^{\circ}$, respectively.

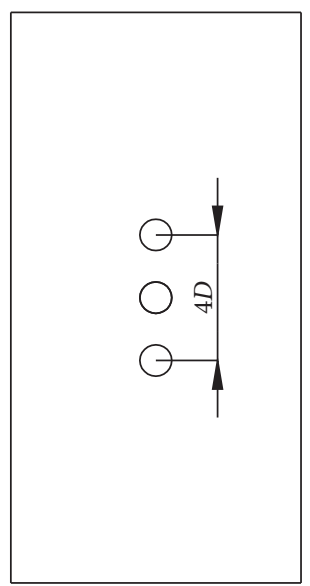

(a)

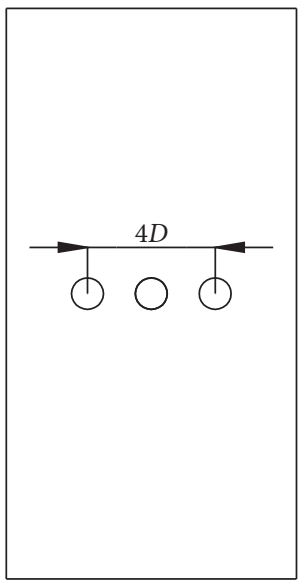

(b)

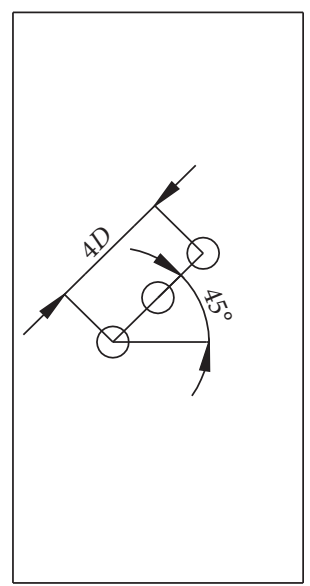

(c)

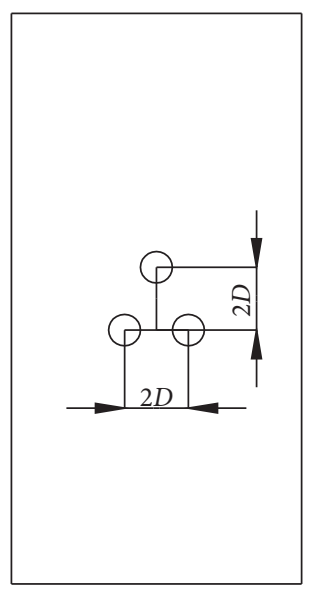

(d)

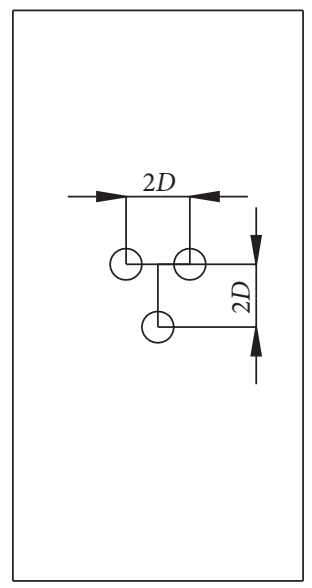

(e)

FIGURE 7: Numerical test samples with different boreholes arrangement form. The arrangement form of (a), (b), (c), (d), and (e) are vertical layout, horizontal layout, inclined layout, up three-flower layout, and down three-flower layout, respectively.

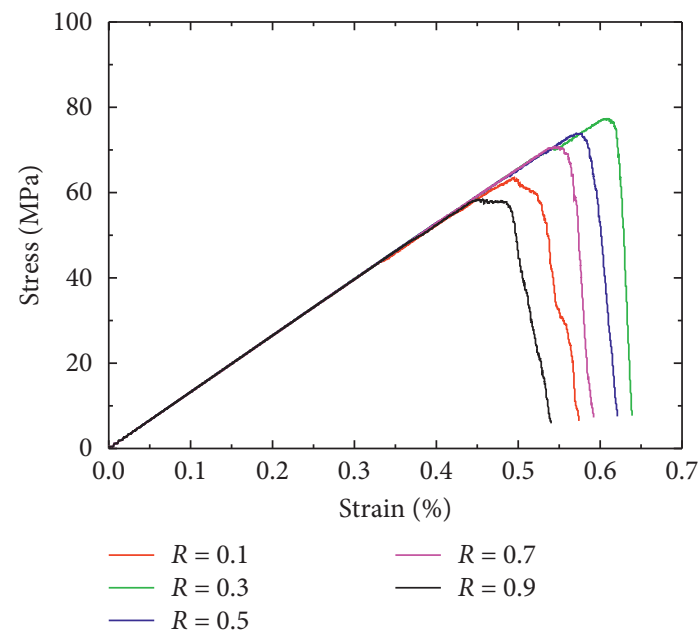

FIgURE 8: Stress-strain curves of rock samples with different drilling positions.

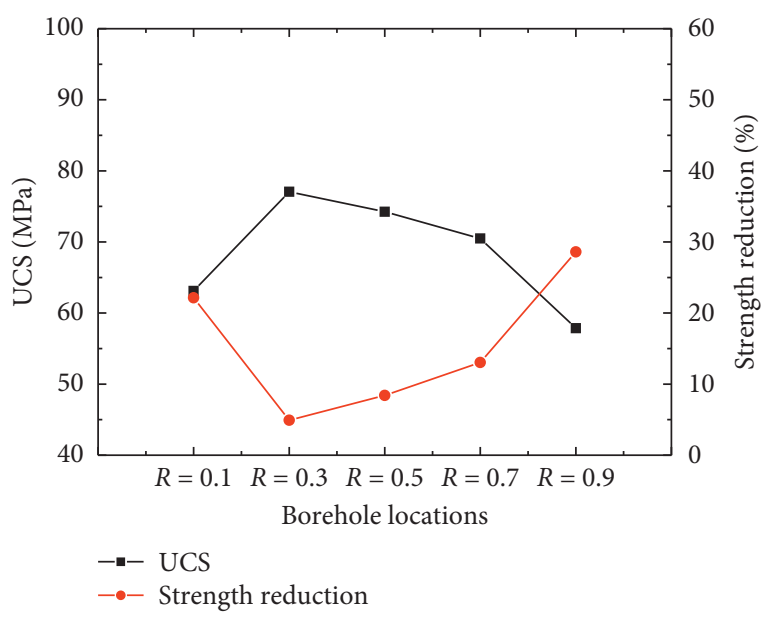

FIGURE 9: Strength reduction curves of rock samples with different drilling positions. 


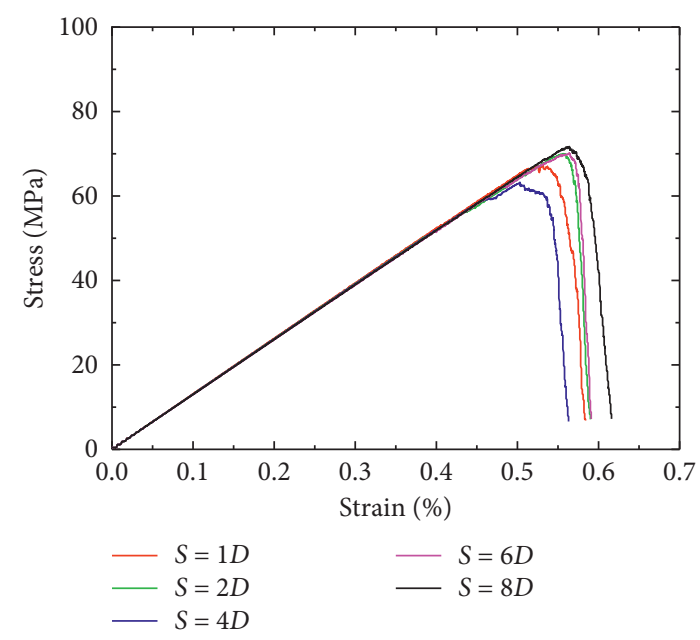

Figure 10: Stress-strain curves of rock samples with different boreholes spacing.

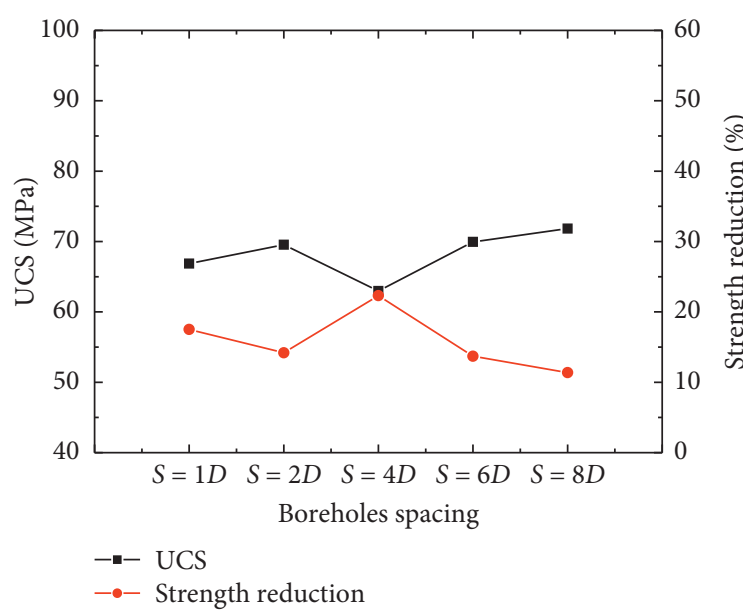

FIGURE 11: Strength reduction curves of rock samples with different boreholes spacing.

can be seen that the compressive strength of rock samples shows an increase-decrease-increase trend with the increase of boreholes spacing. The compressive strengths of the rock samples are $66.87 \mathrm{MPa}, 69.55 \mathrm{MPa}, 62.97 \mathrm{MPa}, 69.95 \mathrm{MPa}$, and $71.84 \mathrm{MPa}$ as the drilling spacing increases from $1 D$ to $8 D$. The corresponding strength reduction degree of theses rock samples shows the trend of decrease-increase-decrease. With the increase of the drilling distance, the strength reduction degrees are $17.5 \%, 14.2 \%, 22.3 \%, 13.7 \%$, and $11.4 \%$, respectively. Therefore, the notion that the larger the boreholes spacing is, the better the pressure relief effect is does not apply. The boreholes spacing with the best pressure relief effect is about 4 times of the borehole diameter.

3.1.3. Influence of Boreholes Dip Angles. Figures 12 and 13 are stress-strain curves and strength reduction curves of rock samples with different boreholes dip angle. From the figures it can be seen that the compressive strength of rock samples shows a trend of increases firstly and then decreases with the

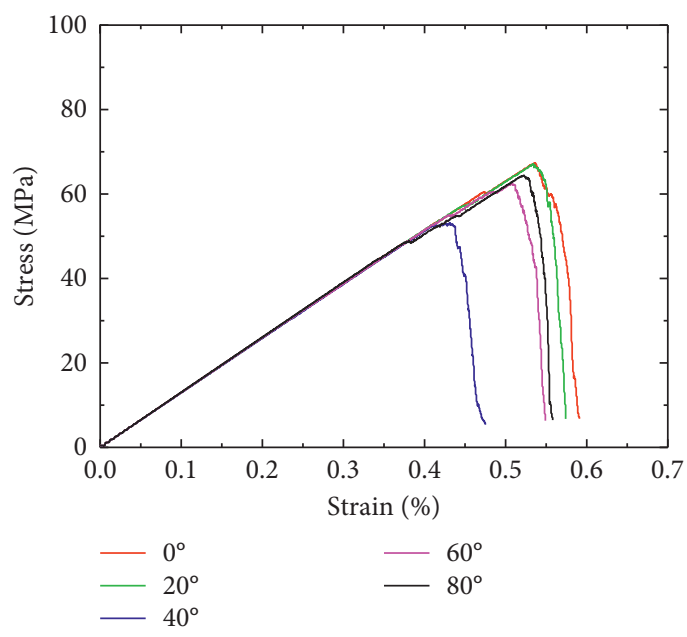

FIgURE 12: Stress-strain curves of rock samples with different boreholes dip angles.

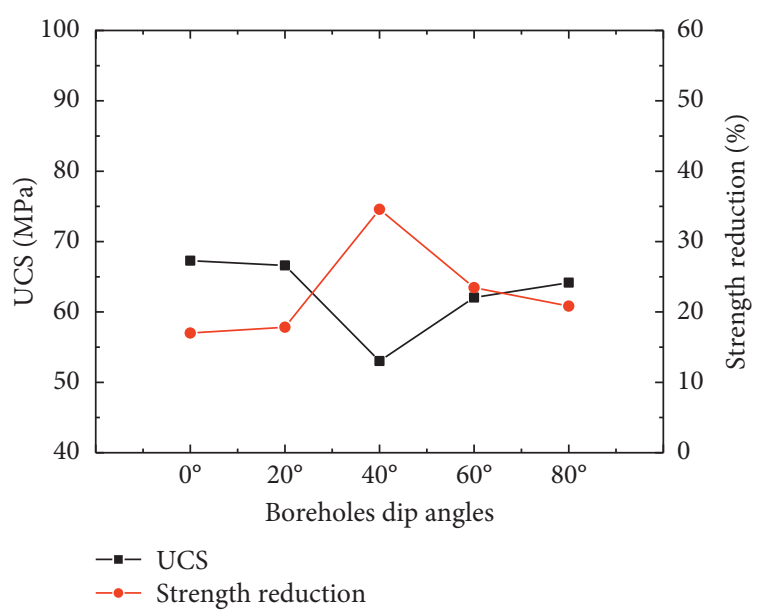

FIGURE 13: Strength reduction curves of rock samples with different boreholes dip angles.

increase of boreholes dip angle. The compressive strengths of the rock samples are $67.28 \mathrm{MPa}, 66.61 \mathrm{MPa}, 53.03 \mathrm{MPa}$, 62.04 MPa, and $64.17 \mathrm{MPa}$. The corresponding strength reduction degree of theses rock samples shows the trend of decrease firstly and then increase. With the increase of the boreholes dip angles, the strength reduction degrees are 17\%, $17.8 \%, 34.56 \%, 23.5 \%$, and $20.8 \%$, respectively. The reason why the strength of the rock sample with the boreholes dip angle is $40^{\circ}$ the lowest is that the failure mode of the complete rock sample is mostly splitting failure along the $45^{\circ}$ angle, and the $40^{\circ}$ boreholes dip angle is the closest to the failure angle of the intact rock sample. It can be seen that the best way to reduce the pressure of surrounding rock is to arrange the boreholes at about $45^{\circ}$.

3.1.4. Influence of Boreholes Arrangement Forms. Figures 14 and 15 are stress-strain curves and strength reduction curves of rock samples with different boreholes arrangement forms. From the figures it can be seen that the compressive strength 


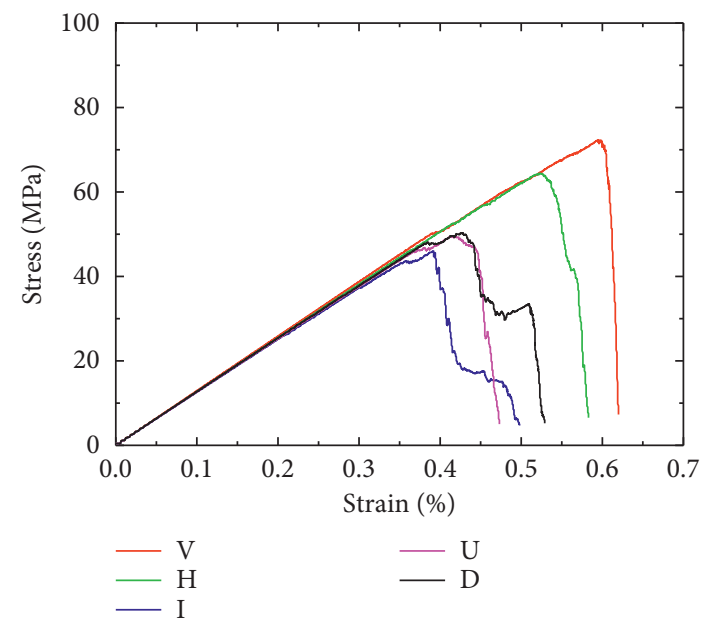

FIgURE 14: Stress-strain curves of rock samples with different boreholes arrangement forms.

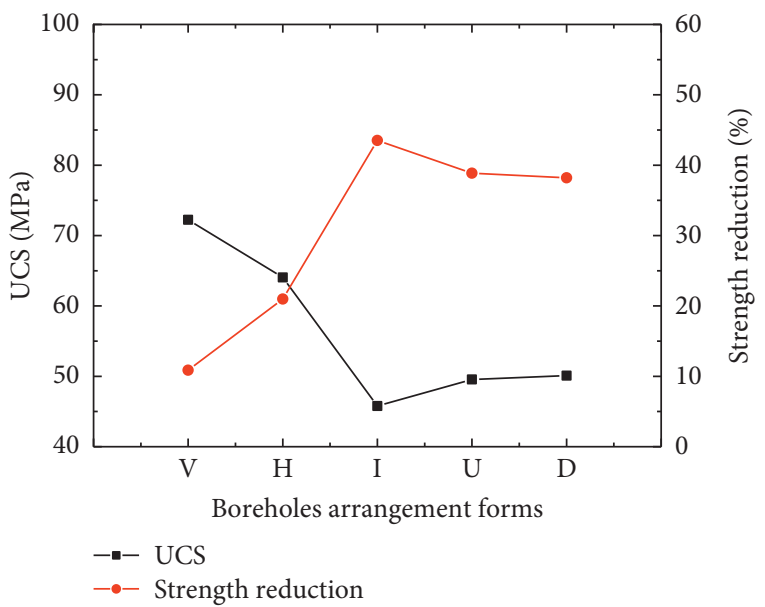

FIGURE 15: Strength reduction curves of rock samples with different boreholes arrangement forms.

of rock sample with an inclined arrangement form is the lowest, $45.78 \mathrm{MPa}$ (corresponding strength reduction degree is $43.5 \%)$. When the arrangement form is up three-flower layout or down three-flower layout, the compressive strength of the rock sample is similar, about $50 \mathrm{MPa}$ (corresponding strength reduction degree is about $38 \%$ ). In addition, when the boreholes arrangement forms are vertical layout and horizontal layout, the compressive strength of the rock samples are $72.25 \mathrm{MPa}$ (corresponding strength reduction degree is $10.9 \%$ ) and $64.05 \mathrm{MPa}$ (corresponding strength reduction degree is $21 \%$ ). Therefore, using the inclined layout and three-flower layout can achieve better pressure relief effect of the surrounding rock mass of the caverns.

3.2. AE Characteristics. When the material receives an external force, the elastic energy stored in the material is quickly released to generate elastic waves and sound, which is called acoustic emission (AE) [18]. For the PFC numerical simulation, the fracture of the parallel bond will release a certain amount of elastic energy. Therefore, the fracture of the bond can be used to reflect the acoustic emission characteristics [19-21]. The numerical acoustic emission of PFC simulation is different from the acoustic emission monitored by the actual test, but there are similarities, which can reflect the characteristics of internal crack damage in rock materials. In this paper, the AE characteristics of different drilling schemes are analyzed based on the number of $\mathrm{AE}$ counts (the number of bonds breakages).

3.2.1. Influence of Borehole Locations. Figure 16 shows the stress-time-AE counts of samples with different borehole height ratio. The $R$ of (a), (b), (c), (d), and (e) are $0.1,0.3,0.5$, 0.7 , and 0.9 , respectively. It can be seen from the figures that the position of the borehole has little influence on the evolution law of acoustic emission, and all go through silent emission stage, slow increase stage, and rapid increase stage. However, the maximum value of acoustic emission counts and the corresponding occurrence time of the rock samples are changed under different drilling positions. As the $R$ increase from 0.1 to 0.9 , the maximum values of the acoustic emission counts are 20 times, 28 times, 22 times, 35 times, and 17 times and the corresponding occurrence time are 54343 steps, 59918 steps, 57138 steps, 55675 steps, and 51929 steps. As $R$ increase, the maximum value of the acoustic emission counts of the samples shows a state of fluctuation. However, the corresponding occurrence time shows a trend of increase firstly and then decrease, which are consistent with the change of the UCS. This shows that the acoustic emission can effectively monitor the stability of the surrounding rock of the caverns. However, the threshold value and the occurrence time of the acoustic emission of the cavern instability changed after the cavern surrounding rock is drilled holes. If the borehole is arranged at the upper part of the cavern, the occurrence time of the cavern instability will be advanced.

3.2.2. Influence of Boreholes Spacing. Figure 17 shows the stress-time-AE counts of samples with different boreholes spacing. The $S$ of (a), (b), (c), (d), and (e) are $1 D, 2 D, 4 D, 6 D$, and $8 D$, respectively. Similar to the influence of drilling positions, the boreholes spacing also has little influence on the evolution law of acoustic emission, and all go through silent emission stage, slow increase stage, and rapid increase stage. In addition, the maximum value of acoustic emission counts and the corresponding occurrence time of the rock samples are changed as the boreholes spacing increase. As the boreholes spacing $S$ increases from $1 D$ to $8 D$, the maximum values of the acoustic emission counts are 21 times, 28 times, 25 times, 26 times, and 21 times and the corresponding occurrence times are 54475 steps, 55075 steps, 53378 steps, 55675 steps, and 57987 steps. Similar to the influence of drilling positions, as $S$ increases, the maximum value of the acoustic emission counts of the samples shows a state of fluctuation. However, the corresponding occurrence time shows a consistent trend (increase-decrease-increase) with the change of the UCS. 


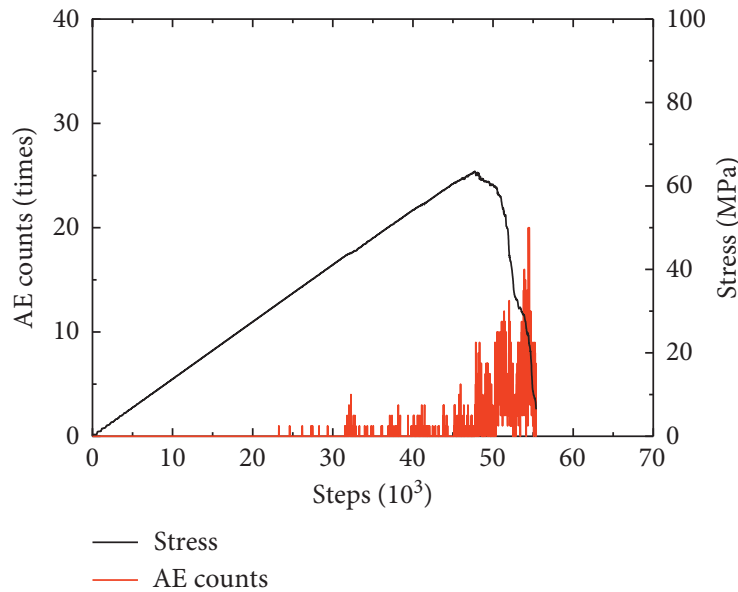

(a)

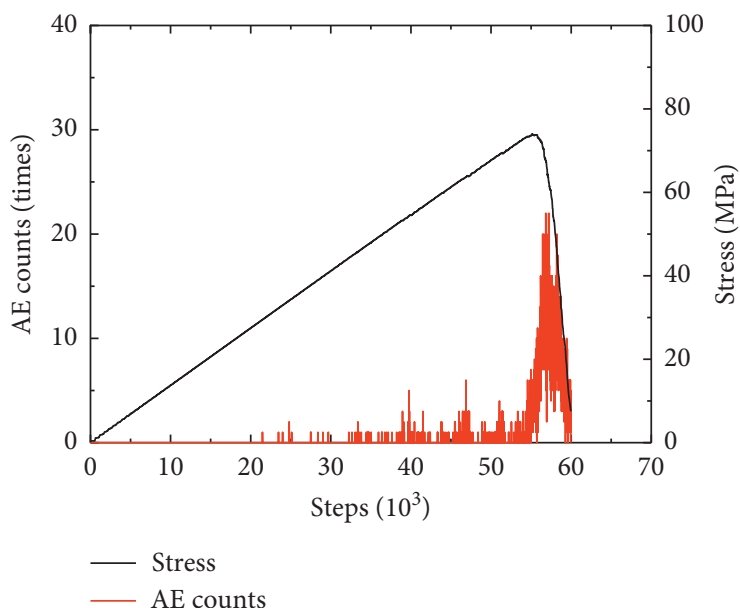

(c)

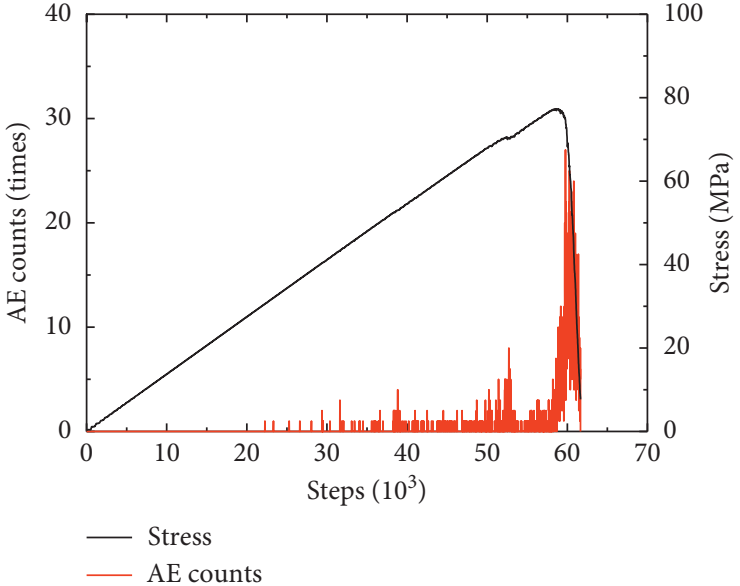

(b)

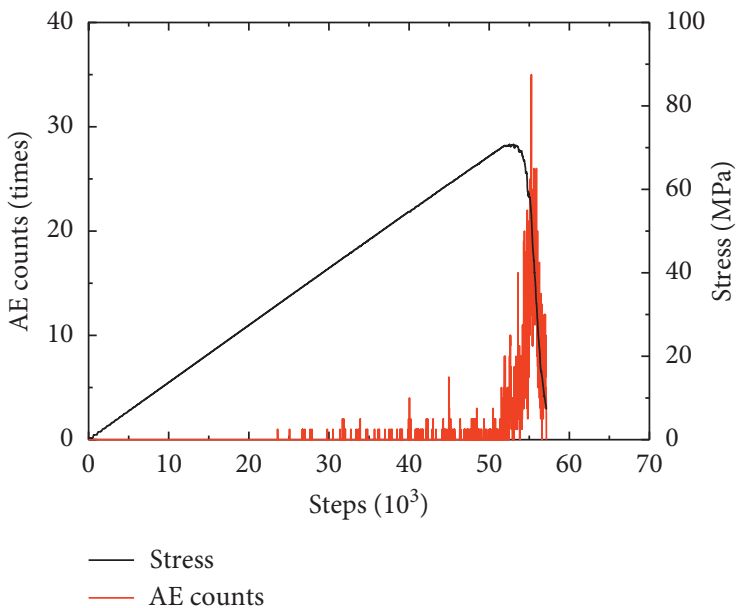

(d)

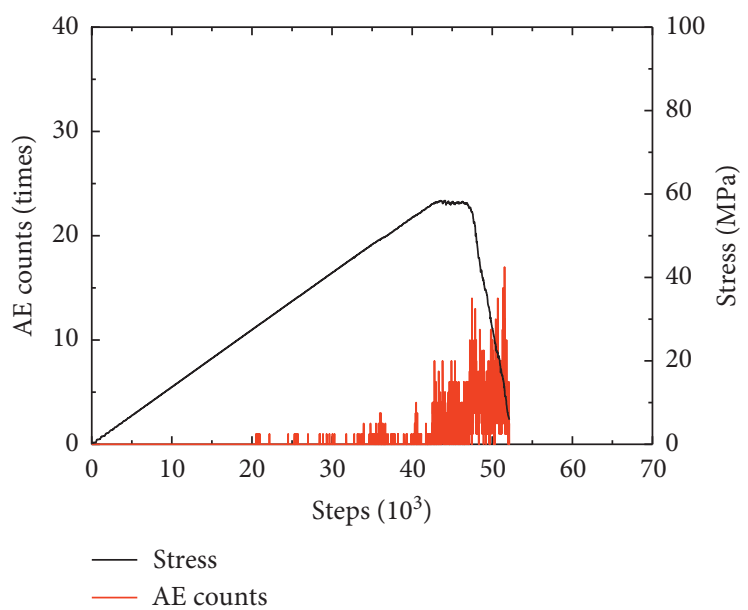

(e)

Figure 16: Stress-time-AE counts of samples with different borehole height ratio. The $R$ of (a), (b), (c), (d), and (e) are $0.1,0.3,0.5,0.7$, and 0.9 , respectively.

3.2.3. Influence of Boreholes Dip Angles. Figure 18 shows the stress-time-AE counts of samples with different boreholes dip angles. The dip angles $\alpha$ of (a), (b), (c), (d), and (e) are $0^{\circ}, 20^{\circ}, 40^{\circ}, 60^{\circ}$, and $80^{\circ}$, respectively. Similar to the influence of drilling positions and boreholes spacing, the boreholes dip angle also has little influence on the evolution law of acoustic emission, and all go through silent emission stage, slow increase stage, and rapid 


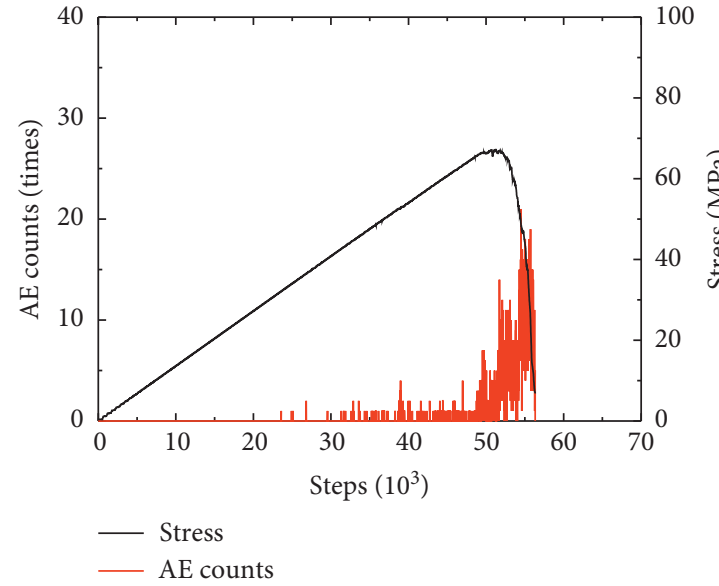

(a)

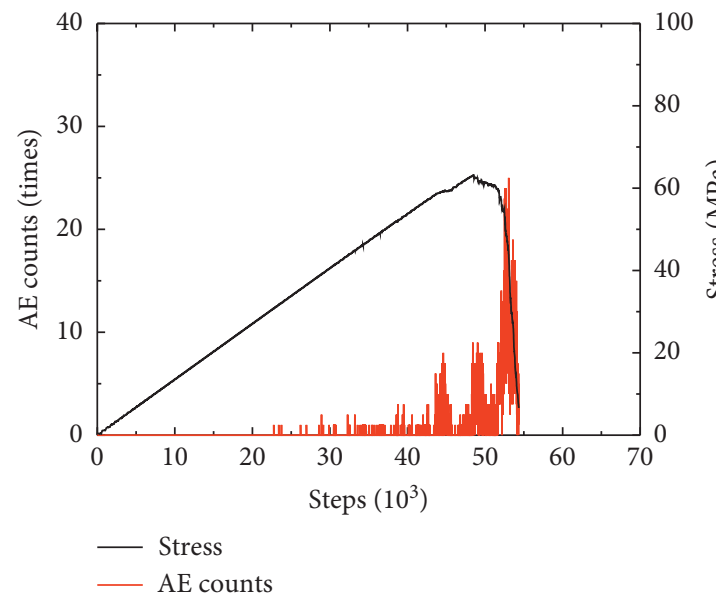

(c)

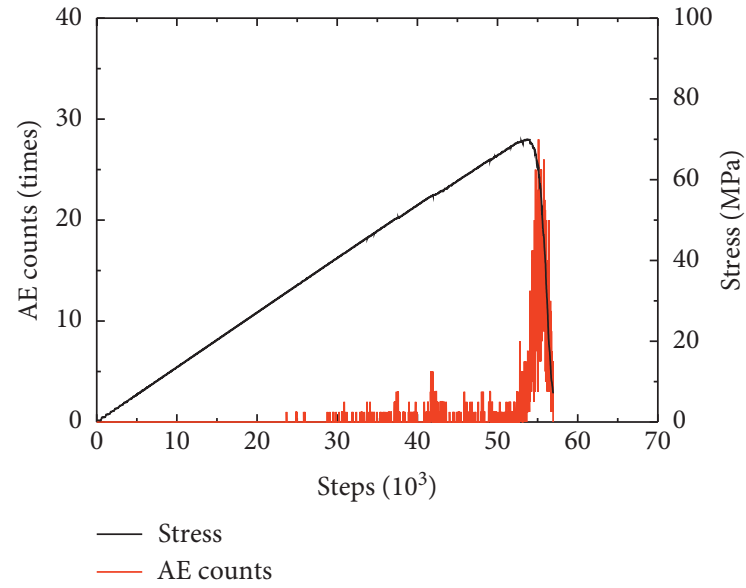

(b)

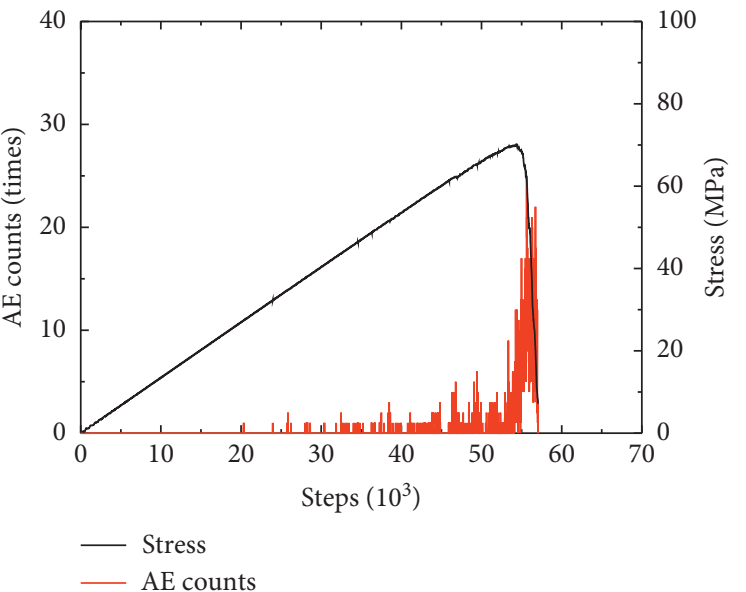

(d)

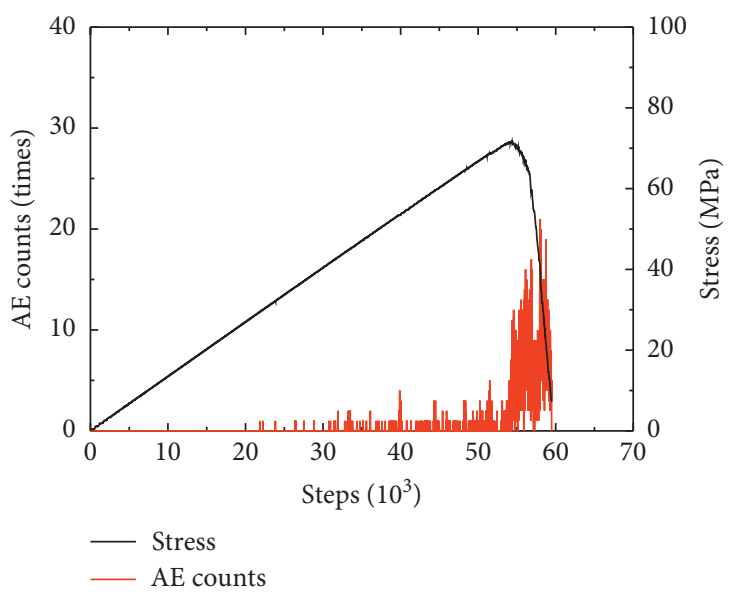

(e)

Figure 17: Stress-time-AE counts of samples with different boreholes spacing. The $S$ of (a), (b), (c), (d), and (e) are $1 D, 2 D, 4 D, 6 D$, and $8 D$, respectively.

increase stage. In addition, the maximum value of acoustic emission counts and the corresponding occurrence time of the rock samples are changed as the boreholes dip angles increase. As the boreholes dip angle increase from $0^{\circ}$ to $80^{\circ}$, the maximum value of the acoustic emission counts are 30 times, 33 times, 12 times, 23 times, and 21 times and the corresponding occurrence times are 55924 steps, 53744 steps, 43808 steps, 52295 steps, and 52646 steps. Similar to the influence of drilling positions and boreholes spacing, as the dip angle $\alpha$ increase, the maximum value of the acoustic emission counts of the samples shows a state of fluctuation. 


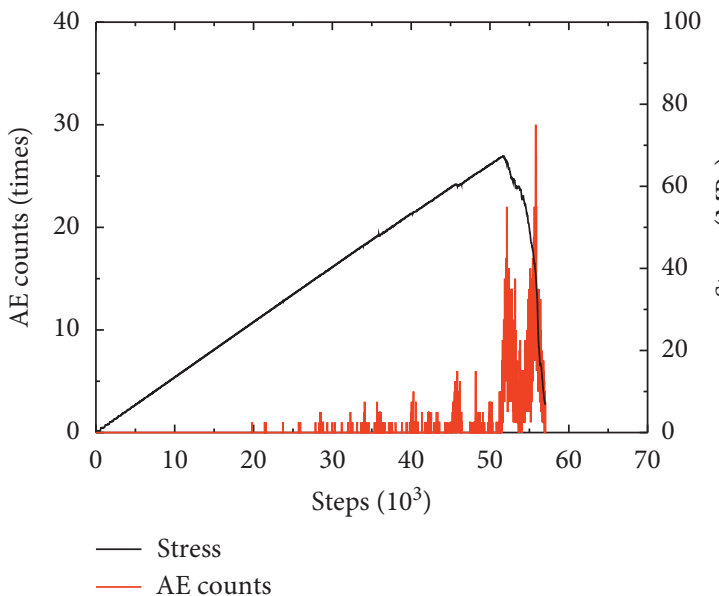

(a)

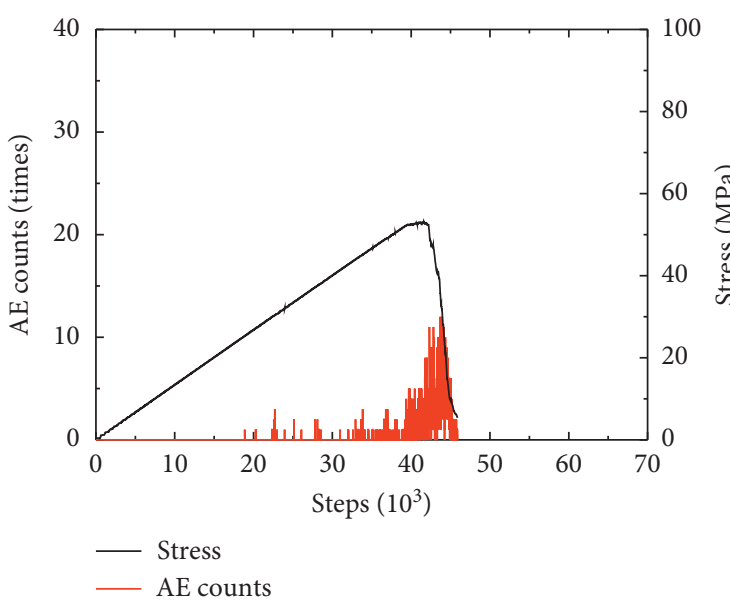

(c)

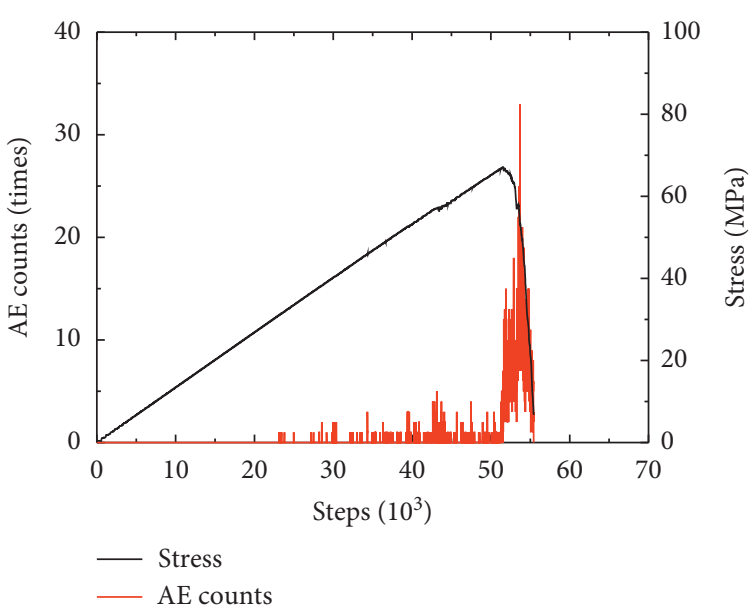

(b)

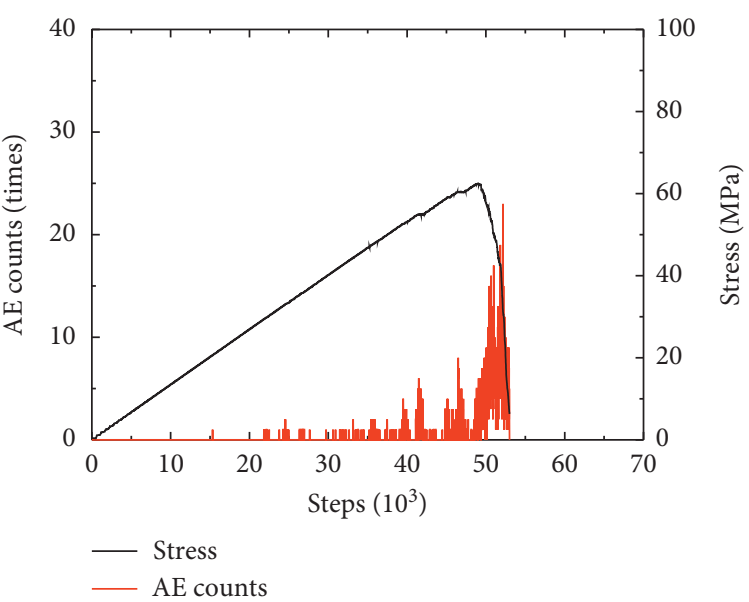

(d)

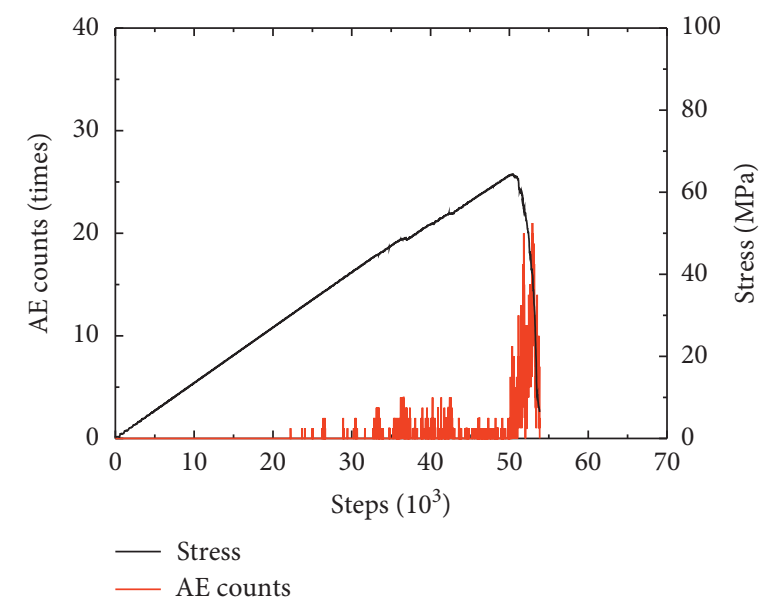

(e)

FIGURE 18: Stress-time-AE counts of samples with different boreholes dip angle. The $\alpha$ of (a), (b), (c), (d), and (e) are $0^{\circ}, 20^{\circ}, 40^{\circ}, 60^{\circ}$, and $80^{\circ}$, respectively.

3.2.4. Influence of Boreholes Arrangement Forms. Figure 19 shows the stress-time-AE counts of samples with different boreholes arrangement forms. The arrangement forms of (a), (b), (c), (d), and (e) are vertical layout, horizontal layout, inclined layout, up three-flower layout, and down three-flower layout, respectively. Similar to the influence of drilling positions, boreholes spacing, and borehole dip angles, the boreholes arrangement forms also have little influence on the evolution law of acoustic emission, and all go through silent emission stage, slow 
increase stage, and rapid increase stage. The difference is that there are two or more peaks in the third stage of acoustic emission rapid increase. This is because the number of drilling holes is three, more than one and two, which makes the mechanical properties of rock samples changed to serious, leading to the stress of rock samples before and after the peak is in a state of fluctuation. Similar to the influence of drilling positions, boreholes spacing, and boreholes dip angles, as the boreholes arrangement forms change, the maximum value of the acoustic emission counts of the samples shows a state of fluctuation. However, the corresponding occurrence time shows a consistent trend with the change of the UCS. When the boreholes arrangement form is vertical layout, the maximum value of the acoustic emission counts and its occurrence time are 27 times and 58586 steps; when the boreholes arrangement form is horizontal layout, the maximum value of the acoustic emission counts and its occurrence time are 26 times and 55675 steps; when the boreholes arrangement form is inclined layout, the maximum value of the acoustic emission counts and its occurrence time are 13 times and 38716 steps; when the boreholes arrangement form is up three-flower layout, the maximum value of the acoustic emission counts and its occurrence time are 17 times and 43559 steps; when the boreholes arrangement form is down three-flower layout, the maximum value of the acoustic emission counts and its occurrence time are 17 times and 49749 steps.

3.3. Failure Modes. It can be seen from Figure 3 that the failure mode of intact rock is inclined split failure with two large fracture face, which is taken as a reference when analyzing the influence of drilling layout on the failure modes of surrounding rock samples.

3.3.1. Influence of Borehole Locations. Figure 20 shows the failure modes of rock samples with different borehole height ratio. The $R$ of (a), (b), (c), (d), and (e) are $0.1,0.3,0.5,0.7$, and 0.9 , respectively. It can be seen from the figures that the failure modes of rock samples with different drilling positions are different from the of intact rock sample. When $R=0.1$, the failure mode of rock sample is mainly at the bottom of the rock sample, which is similar to "V" shape; when $R=0.3$, the failure mode of rock sample is also mainly concentrated at the bottom of the rock sample, which is similar to "W" shape; when $R=0.5$, the failure mode of rock sample is approximately $\mathrm{X}$-shaped; when $R=0.7$, the failure mode of rock sample is approximately Y-shaped; when $R=0.9$, the failure mode of rock sample is approximately inverted " $\sqrt{ }$ " shape. The failure of rock samples is caused by cracks (stress concentration) near the borehole first, and then the whole rock samples are damaged. Drilling can not only lead to the strength reduction of rock mass but also control the failure mode of rock mass. The actual project can control the pressure relief range of drilling with this advantage.
3.3.2. Influence of Boreholes Spacing. Figure 21 shows the failure modes of rock samples with different boreholes spacing. The $S$ of (a), (b), (c), (d), and (e) are $1 D, 2 D, 4 D, 6 D$, and $8 D$, respectively. From the figures it can be obtained that the failure modes of rock samples with different boreholes spacing are different from those of intact rock sample. When $S=1 D$ and $2 D$, the failure modes of rock samples are similar to "X" shape; when $S=4 D$ and $6 D$, the failure modes of rock samples are inclined split failure, similar to "/" shape; when $S=8 D$, the failure mode of rock sample is approximately $\mathrm{n}$-shaped. The smaller the distance between the boreholes is, the more obvious the coupling effect between the boreholes is, and the stronger the damage degree near the boreholes is. However, there is also a waste of drilling. Therefore, the drilling spacing should be reasonably arranged in the actual project. This study shows that when the boreholes spacing is 4 times the hole diameter, the pressure relief effect is the best.

3.3.3. Influence of Boreholes Dip Angles. Figure 22 shows the failure modes of rock samples with different boreholes dip angles. The dip angle $\alpha$ of (a), (b), (c), (d), and (e) are $0^{\circ}, 20^{\circ}$, $40^{\circ}, 60^{\circ}$, and $80^{\circ}$, respectively. From the figures it can be obtained that the failure modes of rock samples with different boreholes dip angle are also different from those of intact rock sample. When $\alpha=0^{\circ}$, the failure mode of the rock sample is approximately inverted "V" shape; when $\alpha=20^{\circ}$, the failure mode of the rock sample is approximate to " $\mathrm{H}$ " shape; when $\alpha=40^{\circ}$ and $80^{\circ}$, the failure modes of the rock samples are similar to " $y$ " shape; when $\alpha=60^{\circ}$, the failure modes of the rock samples are similar to " $X$ " shape. The smaller the boreholes dip angle is, the more likely the failure mode of the rock sample concentrated in the middle of the sample is; the larger the boreholes dip angle is, the more likely it can lead to splitting failure of rock samples.

3.3.4. Influence of Boreholes Arrangement Forms. Figure 23 shows the failure modes of rock samples with different boreholes arrangement forms. The arrangement forms of (a), (b), (c), (d), and (e) are vertical layout, horizontal layout, inclined layout, up three-flower layout, and down threeflower layout, respectively. From the figures it can be obtained that the failure modes of rock samples with different boreholes arrangement forms are also different from those of intact rock sample. When the boreholes arrangement form is vertical layout, the failure mode of the sample is similar to " $\sqrt{ }$ " shape; when the boreholes arrangement form is horizontal layout, the failure mode of the sample is similar to " $\mathrm{H}$ " shape; when the boreholes arrangement form is inclined layout, the failure mode of the sample is similar to symmetrical " $h$ " shape; when the boreholes arrangement form is up three-flower layout, the failure mode of the sample is similar to inverted "Y" shape; when the boreholes arrangement form is down three-flower layout, the failure mode of the sample is similar to " $Y$ " shape. In addition, the inclined drill holes are more likely to lead to the propagation and penetration of rock cracks, even if the number of cracks is less. 


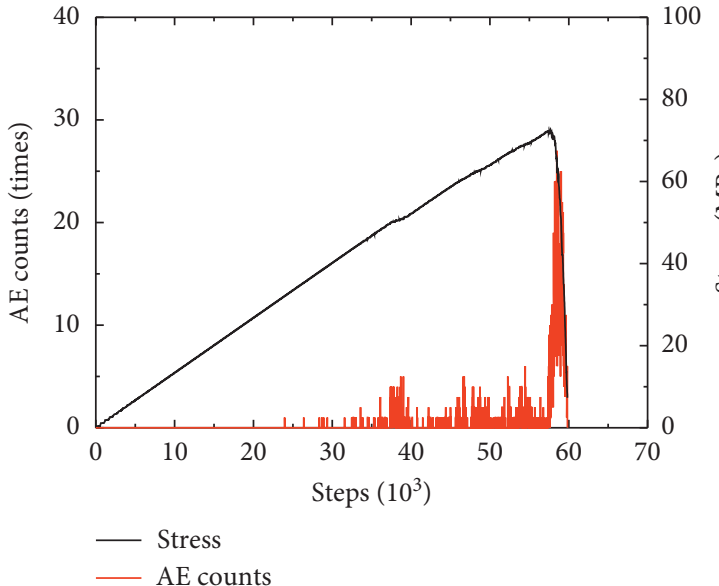

(a)

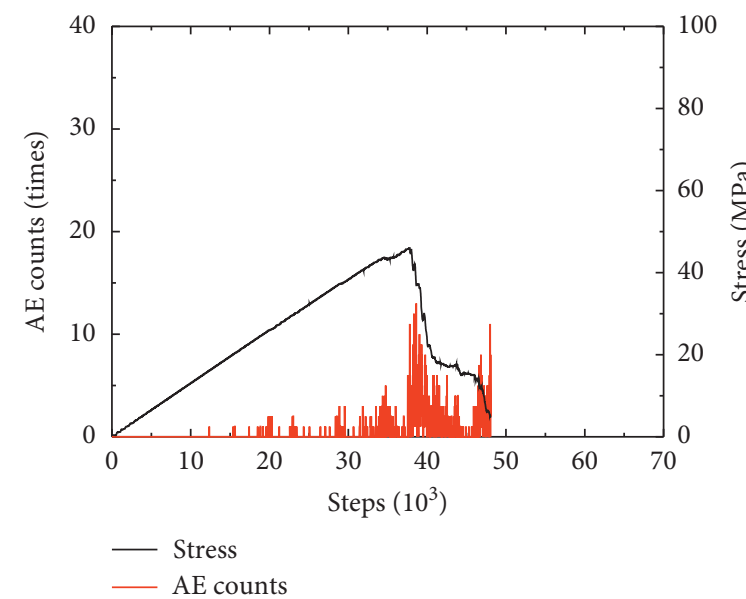

(c)

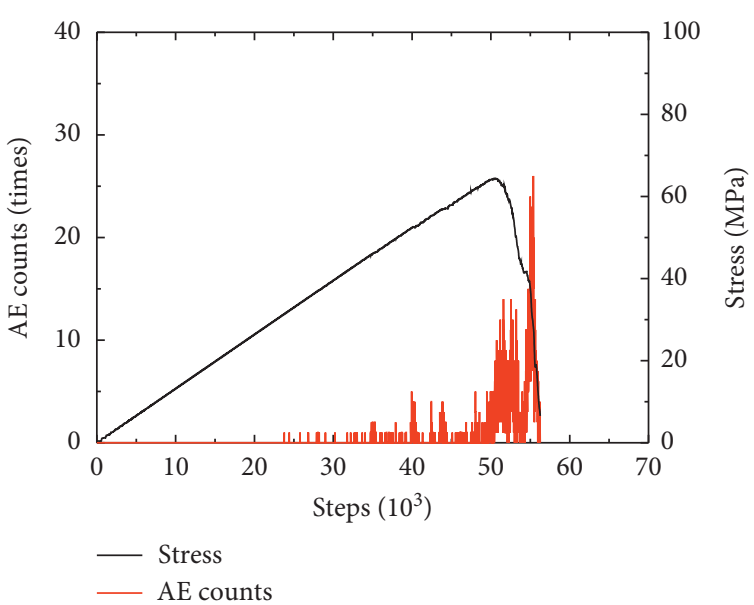

(b)

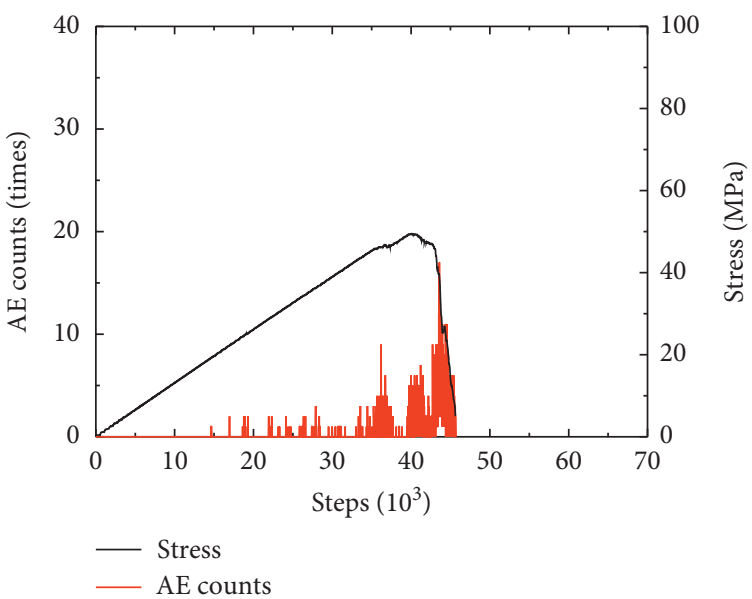

(d)

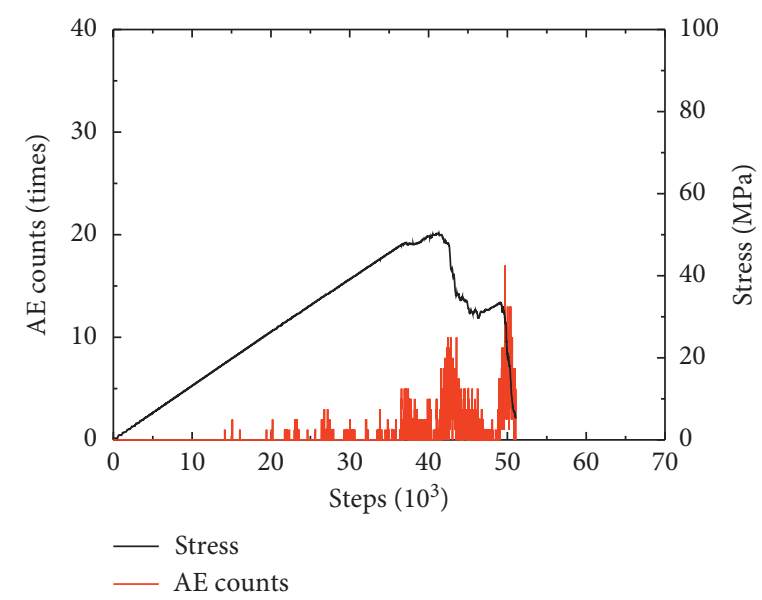

(e)

FIGURE 19: Stress-time-AE counts of samples with different boreholes arrangement form. The arrangement forms of (a), (b), (c), (d), and (e) are vertical layout, horizontal layout, inclined layout, up three-flower layout, and down three-flower layout, respectively. 


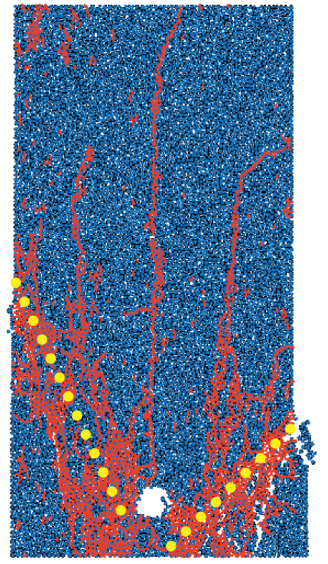

(a)

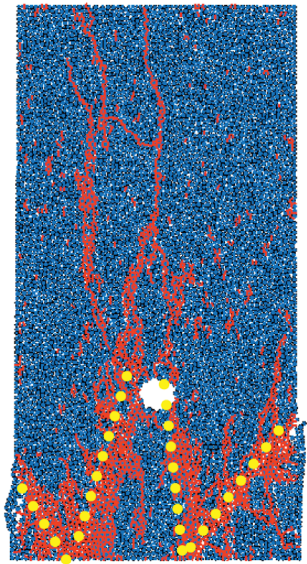

(b)

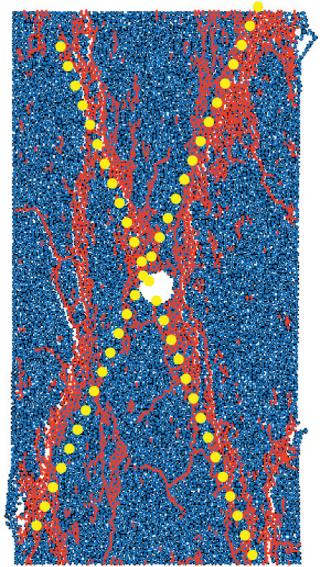

(c)

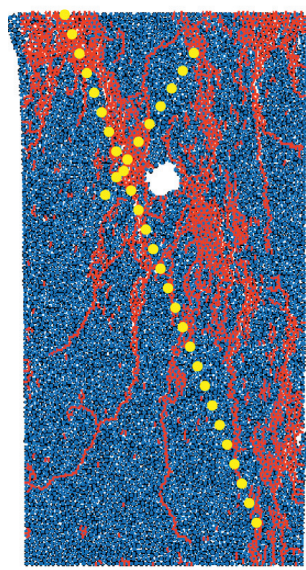

(d)

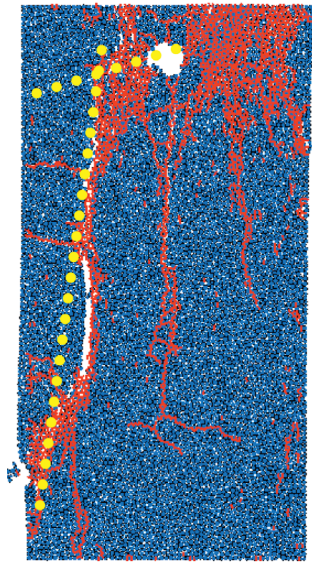

(e)

Figure 20: Failure modes of samples with different borehole height ratio. The $R$ of (a), (b), (c), (d), and (e) are 0.1, 0.3, 0.5, 0.7, and 0.9, respectively.

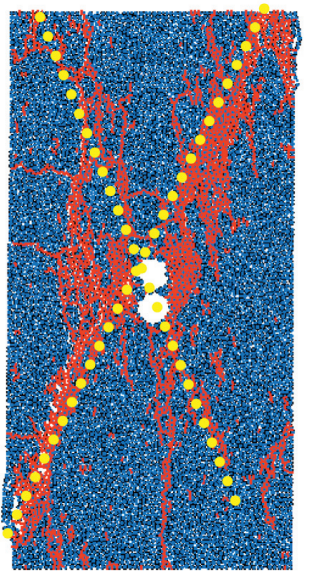

(a)

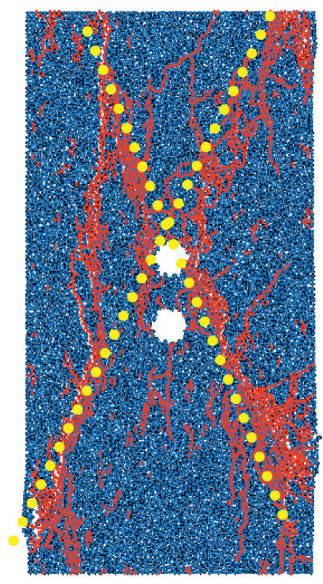

(b)

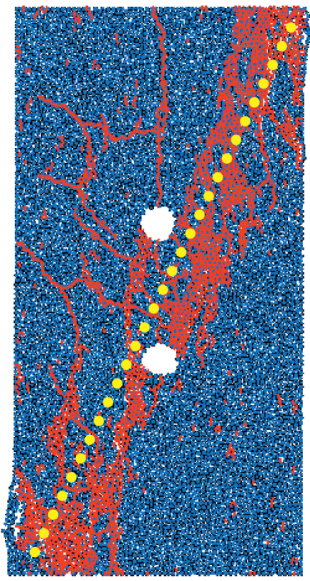

(c)

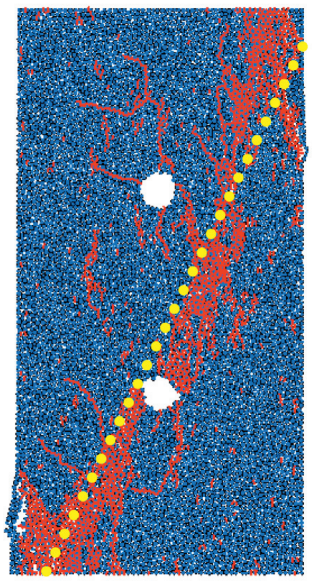

(d)

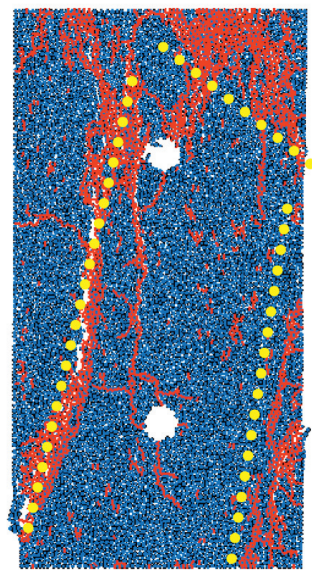

(e)

Figure 21: Failure modes of samples with different boreholes spacing. The $S$ of (a), (b), (c), (d), and (e) are $1 D, 2 D, 4 D, 6 D$, and $8 D$, respectively.

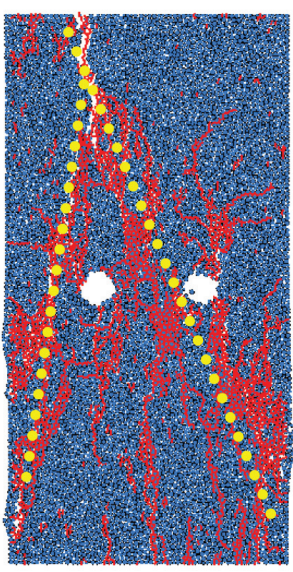

(a)

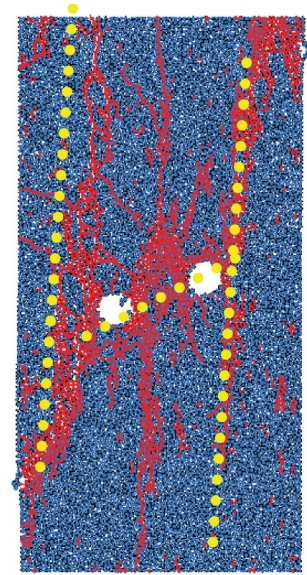

(b)

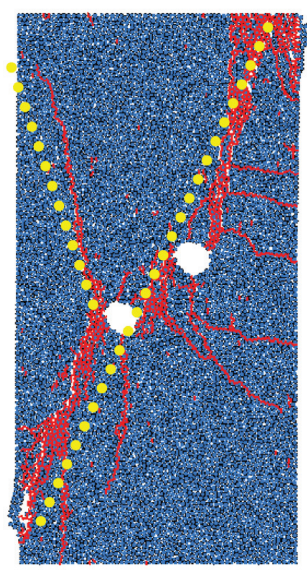

(c)

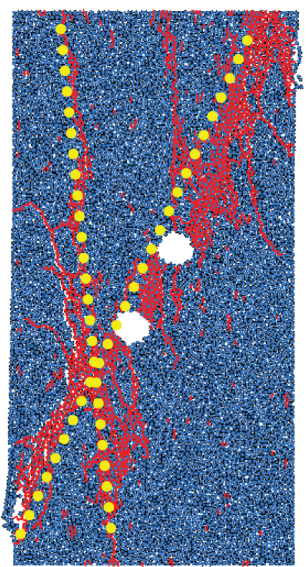

(d)

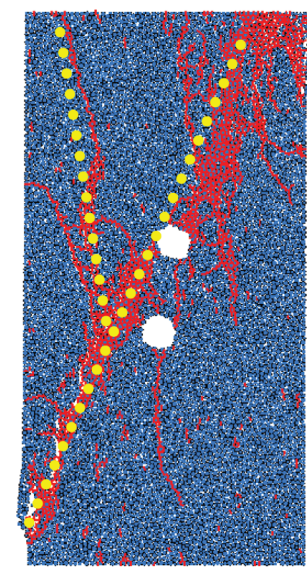

(e)

Figure 22: Failure modes of samples with different boreholes dip angle. The $\alpha$ of (a), (b), (c), (d), and (e) are $0^{\circ}, 20^{\circ}, 40^{\circ}, 60^{\circ}$, and $80^{\circ}$, respectively. 


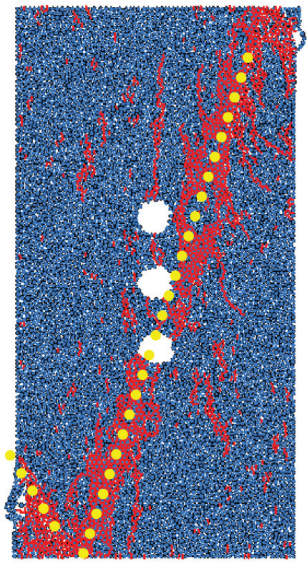

(a)

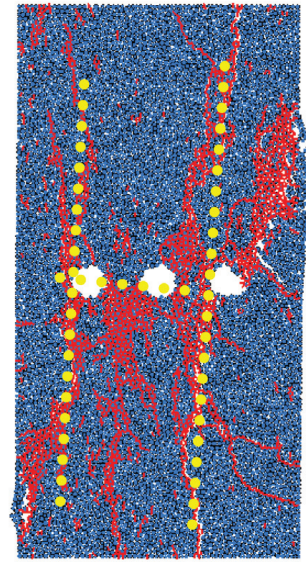

(b)

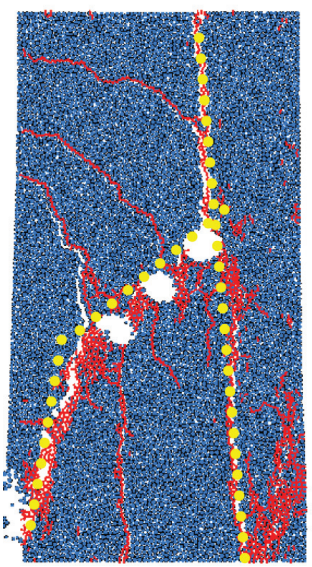

(c)

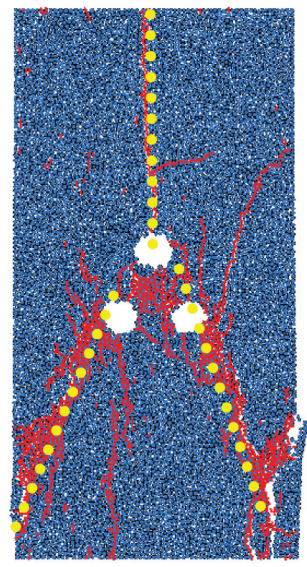

(d)

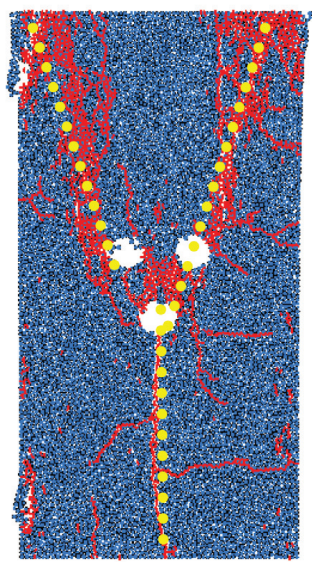

(e)

Figure 23: Failure modes of samples with different boreholes arrangement forms. The arrangement forms of (a), (b), (c), (d), and (e) are vertical layout, horizontal layout, inclined layout, up three-flower layout, and down three-flower layout, respectively.

\section{Conclusions and Suggestions}

The strength reduction degrees of rock samples with different drilling layout schemes are different. In addition to the sample that the drill hole is at the end face of the rock bottom $(R=0.1)$, the closer the drilling hole is to the top of the rock sample, that is, the larger the $R$ value is, the higher the strength reduction degree of the rock sample is. It is easy to reduce the stress concentration of surrounding rock mass by drilling at the top and bottom of the cavern. The strength reduction degree of rock samples shows a decrease-increase-decrease trend with the increase of boreholes spacing. The boreholes spacing with the best pressure relief effect is about 4 times of the borehole diameter. The strength reduction degree of rock samples shows a trend of decrease firstly and then increase with the increase of boreholes dip angle. The best way to reduce the pressure of surrounding rock is to arrange the boreholes at about $45^{\circ}$. The strength reduction degree of rock sample with an inclined arrangement form is the largest, followed by the arrangement form being up three-flower layout or down three-flower layout. Using the inclined layout and threeflower layout can achieve better pressure relief effect of the surrounding rock mass of the caverns.

The rock samples with different drilling layout schemes have little influence on the evolution law of acoustic emission, and all go through silent emission stage, slow increase stage, and rapid increase stage. However, the maximum value of acoustic emission counts and the corresponding occurrence time of the rock samples are changed. As the drilling layout schemes change, the maximum value of the acoustic emission counts of the samples shows a state of fluctuation. However, the changed trend of the occurrence time of the maximum value of the acoustic emission counts is consistent with the change of the UCS. The acoustic emission can effectively monitor the stability of the surrounding rock of the caverns. However, the threshold value and the occurrence time of the acoustic emission of the cavern instability changed after the cavern surrounding rock is drilled holes. If the borehole is arranged at the surrounding rock mass, the occurrence time of the cavern instability may be advanced.

The failure modes of rock samples with different drilling layout schemes are different. The shapes of the failure modes of the rock samples with different borehole location are "V" $(R=0.1), " W "(R=0.3), \quad " \mathrm{X} "(R=0.5), \quad " Y "(R=0.7)$, and " $\sqrt{ }$ " $(R=0.9)$. The shapes of the failure modes of the rock samples with different boreholes spacing are " $\mathrm{X}$ " $(S=1 D$ or $2 D)$, "/" $(S=4 D$ or $6 D)$, and " $n$ " $(S=8 D)$. The shapes of the failure modes of the rock samples with different boreholes dip angles are "V" $\left(\alpha=0^{\circ}\right)$, "H" $\left(\alpha=20^{\circ}\right)$, “y" $\left(\alpha=40^{\circ}\right.$ or $\left.80^{\circ}\right)$, and " $\mathrm{X}$ " $\left(\alpha=60^{\circ}\right)$. The shapes of the failure modes of the rock samples with different boreholes arrangement forms are " $\sqrt{ }$ " (vertical layout), "H" (horizontal layout), symmetrical " $h$ " (inclined layout), inverted "Y" (up three-flower layout), and "Y" (down three-flower layout). The failure of rock samples is caused by cracks near the borehole first, and then the whole rock samples are damaged. Drilling can not only lead to the strength reduction of rock mass but also control the failure mode of rock mass. The actual project can control the pressure relief range of drilling with this advantage.

\section{Data Availability}

All the data generated or analyzed during this study are included in this published article.

\section{Conflicts of Interest}

The authors declare that they have no conflicts of interest.

\section{Acknowledgments}

The research described in this paper was financially supported by Liaocheng University Research Fund (no. 318051703). 


\section{References}

[1] Y. Pan, Z. Li, and M. Zhang, "Distribution, type mechanism and prevention of rockburst in China," Chinese Journal of Rock Mechanics and Engineering, vol. 22, no. 11, pp. 18441851, 2003.

[2] P. Konicek, K. Soucek, L. Stas, and R. Singh, "Long-hole destress blasting for rockburst control during deep underground coal mining," International Journal of Rock Mechanics and Mining Sciences, vol. 61, pp. 141-153, 2013.

[3] J. H. Liu, F. X. Jiang, G. J. Sun et al., "Mechanism of intensive venting pulverized coal to prevent coal burst and its application," Chinese Journal of Rock Mechanical Engineering, vol. 33, no. 4, pp. 747-754, 2014.

[4] X. Zhang and F. Meng, "Statistical analysis of large accidents in China's coal mines in 2016," Natural Hazards, vol. 92, no. 1, pp. 311-325, 2018.

[5] Z. Zhang, M. Deng, X. Wang et al., "Field and numerical investigations on the lower coal seam entry failure analysis under the remnant pillar," Engineering Failure Analysis, vol. 115, 2020.

[6] E. B. Yi, Z. L. Mu, L. M. Dou et al., "Study on comparison and analysis on pressure releasing effect of boreholes in soft and hard seam," Coal Science and Technology, vol. 39, no. 6, pp. 1-5, 2011.

[7] Y. Li, H. Zhang, Z. Zhu et al., "Study on safety parameters of pressure relief borehole in rockburst coal seam," China Safety Science Journal, vol. 28, no. 11, pp. 122-128, 2018.

[8] S. Zhang, Y. Li, B. Shen, X. Sun, and L. Gao, "Effective evaluation of pressure relief drilling for reducing rock bursts and its application in underground coal mines," International Journal of Rock Mechanics and Mining Sciences, vol. 114, pp. 7-16, 2019.

[9] S. Zhu, F. Jiang, X. Shi et al., "Energy dissipation index method for determining rockburst prevention drilling parameters," Rock and Soil Mechanics, vol. 36, no. 8, pp. 2270-2276, 2015.

[10] C. Jia, Y. Jiang, X. Zhang et al., "Laboratory and numerical experiments on pressure relief mechanism of large-diameter boreholes," Chinese Journal of Geotechnical Engineering, vol. 39, no. 6, pp. 1115-1122, 2017.

[11] Q. Zhang, G. Sun, J. Suo et al., "The 3D numerical simulation of deep granite borehole unloading," Chinese Journal of Applied Mechanics, vol. 34, no. 5, pp. 988-994, 2017.

[12] P. A. Cundall and O. D. L. Strack, "A discrete numerical model for granular assemblies," Géotechnique, vol. 29, no. 1, pp. 47-65, 1979.

[13] Itasca Consulting Group, PFC Users' Manual (Version 5.0), Itasca Consulting Group, Minneapolis, MN, USA, 2014.

[14] U. Castro-Filgueira, L. R. Alejano, J. Arzúa, and D. M. Ivars, "Sensitivity analysis of the micro-parameters used in a PFC analysis towards the mechanical properties of rocks," Procedia Engineering, vol. 191, pp. 488-495, 2017.

[15] X. Zhang, N. Louis, and W. Yuen, "Cracking processes in rock-like material containing a single flaw under uniaxial compression: a numerical study based on parallel bondedparticle model approach," Rock Mechanics and Rock Engineering, vol. 45, no. 5, pp. 711-737, 2012.

[16] Y. Xiang, H. Liu, W. Zhang, J. Chu, D. Zhou, and Y. Xiao, "Application of transparent soil model test and DEM simulation in study of tunnel failure mechanism," Tunnelling and Underground Space Technology, vol. 74, pp. 178-184, 2018.
[17] W. Liu, J. Liu, and C. Zhu, "Multi-scale effect of acoustic emission characteristics of 3D rock damage," Arabian Journal of Geosciences, vol. 12, no. 22, 2019.

[18] Y. Cao, J. Wu, L. Chen, P. Wu, and F. Shaikh, "Experimental study on granite acoustic emission and micro-fracture behavior with combined compression and shear loading: phenomenon and mechanism," Scientific Reports, vol. 10, no. 1, 2020.

[19] M. Cai, P. K. Kaiser, H. Morioka et al., "FLAC/PFC coupled numerical simulation of AE in large-scale underground excavations," International Journal of Rock Mechanics and Mining Sciences, vol. 44, no. 4, pp. 550-564, 2007.

[20] X.-P. Zhang, Q. Zhang, and S. Wu, "Acoustic emission characteristics of the rock-like material containing a single flaw under different compressive loading rates," Computers and Geotechnics, vol. 83, pp. 83-97, 2017.

[21] W. Liu, W. Yuan, Y. Yan et al., "Analysis of acoustic emission characteristics and damage constitutive model of coal-rock combined body based on particle flow code," Symmetry, vol. 11, no. 8, 2019. 